\title{
Pengaruh Tehnik Akupresur dan TENS Terhadap Intensitas Nyeri Persalinan Kala I Fase Aktif
}

\author{
Nelly Karlinah ${ }^{1}$, Joserizal Serudji², Iskandar Syarif ${ }^{3}$
}

\begin{abstract}
Abstrak
Pengelolaan nyeri persalinan membutuhkan asuhan sayang ibu. Diperlukan suatu manajemen nyeri dalam persalinan dengan metode non farmakologi, salah satunya akupresur dan Transcutaneous Electrical Nerve Stimulation (TENS) dengan tujuan meningkatkan rasa aman dan nyaman pada ibu bersalin.Tujuan penelitian ini adalah menentukan pengaruh tehnik akupresur dan TENS terhadap intensitas nyeri persalinan kala I fase aktif. Penelitian dilakukan diwilayah kerja Puskesmas Kampar Kiri Tengah dan Puskesmas Perhentian Raja. Jenis penelitian eksperimental dengan post test only control group desain dengan pengambilan sampel secara consecutive sampling. Jumlah sampel 20 responden setiap kelompok total sampel 60 responden. Data dianalisis univariat dan bivariat menggunakan uji chi-square. Proporsi intensitas nyeri dengan kategori sedang pada kelompok intervensi akupresur lebih besar dari pada kelompok kontrol pada pembukaan serviks $4 \mathrm{~cm}$. Berdasarkan uji statistik terdapat pengaruh bermakna dimana nilai $p=0,011(<0,05)$. Terdapat pengaruh yang bermakna antara kelompok intervensi TENS dan kontrol pada pembukaan serviks $8 \mathrm{~cm}$ dengan nilai $p=0,011 \quad(<0,05)$. Kesimpulan pengaruh akupresur lebih baik digunakan pada pembukaan $4 \mathrm{~cm}$, sedangkan pengaruh TENS lebih baik digunakan pada pembukaan $8 \mathrm{~cm}$.
\end{abstract}

Kata kunci: intensitas nyeri, akupresur, TENS

\begin{abstract}
Management of pain labor pain needs safe motherhood. It needs a pain management in labor by using nonpharmacological methods, such as acupressure and Transcutaneous Electrical Nerve Stimulation (TENS) that may increase safety and comfortable in childbirth. The objective of this study was to determine the effect of acupressure and TENS techniques on pain intensity first stage of labor active phase. This study had been done in Kampar Kiri Tengah and Perhentian Raja health care centres. It was an experimental research study with post test only control group design by using consecutive sampling method. Each group consist of 20 respondents so total sample of 60 respondents. The data analyzed by using univariate and chi-square test for bivariate analysis. The proportion of the pain intensity with medium category in the acupressure intervention group is better than control group at $4 \mathrm{~cm}$ cervical dilation. Statistically, there are significant effect whith a $p$ value $=0,011(<0,05)$. There is a significant effect between TENS intervention group and control groups at $8 \mathrm{~cm}$ cervical dilation with $p$ value $=0,011(<0,05)$.It can be concluded that effect of acupressure is better used at the of $4 \mathrm{~cm}$ cervical dilation, while the effect of TENS is better used at $8 \mathrm{~cm}$ cervical dilation
\end{abstract}

Keywords: pain intensity, accupressure, TENS

Affiliasi penulis: 1. Program Studi S2 Magister Kebidanan FK UNAND (Fakultas Kedokteran Universitas Andalas Padang), 2. Bagian Obstetri \& Gynekologi FK UNAND/RSUP Dr. M. Djamil Padang, 3. Bagian Anak FK UNAND/RSUP Dr. M. Djamil Padang Korespondensi: Nelly Karlinah, Simp. Kantor Camat Sei. Pagar Kec. Kampar Kiri Hilir Kab. Kampar Prov. Riau

E-mail: nellykarlinah87@gmail.com, Telp: 085376660876

\section{PENDAHULUAN}

Persalinan merupakan suatu diagnosis klinis yang terdiri dari dua unsur yaitu kontraksi uterus dan dilatasi pembukaan serviks secara progresif. Proses persalinan dapat menimbulkan ketidaknyamanan dan nyeri, oleh karena itu pengalaman melahirkan 
mempunyai potensiyang besar untuk mendapat pereda nyeri yang memuaskan. ${ }^{1,2}$

Pengelolaan nyeri persalinan membutuhkan asuhan sayang ibu dimana sesuai dengan dokumen WHO menjelaskan salah satu cara untuk memberikan asuhan yang bersifat sayang ibu disebut dengan Safe Motherhood yang mempunyai misi untuk mempromosikan kesempurnaan model asuhan persalinan yang dapat meningkatkan hasil kelahiran, model asuhan kebidanan ini mendukung dan melindungi proses kelahiran normal. Badan Coalition for Improving Maternity Services (CIMS) melahirkan Safe Motherhood Initiative merumuskan 10 langkah asuhan sayang ibu dan pada poin ke 7 disebutkan untuk memberikan asuhan persalinan dalam metoda meringankan rasa nyeri tanpa penggunaan obatobatan. $^{3}$

Penelitian di Amerika Serikat mendapatkan $70 \%$ sampai $80 \%$ wanita yang melahirkan mengharapkan persalinan berlangsung tanpa rasa nyeri. Berbagai cara dilakukan agar ibu melahirkan tidak selalu merasa sakit dan akan merasakan nyaman. Saat ini di negara berkembang 20\% hingga $50 \%$ persalinan di rumah sakit dilakukan dengan sectio caesaria, tingginya operasi sectio caesaria disebabkan para ibu yang hendak bersalin lebih memilih operasi yang relatif tidak nyeri. Di Brazil angka ini mencapai lebih dari $50 \%$ dari angka kelahiran di suatu rumah sakit yang merupakan persentase tertinggi di seluruh dunia. Nyeri yang terjadi dapat mempengaruhi kondisi ibu berupa kelelahan, rasa takut, khawatir dan menimbulkan stres. Stres dapat menyebabkan melemahnya kontraksi rahim dan berakibat pada persalinan yang lama. ${ }^{4,5}$

Tounair pada tahun 2007 dalam penelitiannya menyatakan nyeri persalinan ringan terjadi pada $15 \%$ kasus, nyeri sedang $35 \%$, nyeri berat $30 \%$, dan nyeri ektrem terjadi pada $20 \%$ kasus. Kelahiran seorang anak akan menyebabkan timbulnya suatu tantangan mendasar terhadap struktur interaksi keluarga, bagi seorang ibu, melahirkan bayi adalah peristiwa yang sangat membahagiakan sekaligus juga peristiwa yang berat penuh tantangan dan kecemasan. ${ }^{6}$

Berbagai upaya dilakukan untuk menurunkan nyeri pada persalinan, baik secara farmakologi maupun nonfarmakologi. Manajemen nyeri secara farmakologi lebih efektif dibanding dengan metode non-farmakologi. Metode farmakologi lebih mahal dan berpotensi mempunyai efek yang kurang baik, sedangkan metode non-farmakologi lebih murah, simpel, efektif dan tanpa efek yang merugikan. Hal ini dapat dilakukan sebagai upaya yang dilakukan untuk memberikan kenyamanan pada ibu bersalin dan bidan sebagai salah satu tenaga kesehatan juga sangat berperan dalam hal tersebut. ${ }^{7}$

Diperlukan asuhan persalinan untuk mengurangi rasa nyeri, metode non farmakologi diantaranya akupresur. Akupresur adalah suatu tehnik penyembuhan dengan menekan, memijat, mengurut bagian tubuh untuk mengaktifkan peredaran energi Akupresur merupakan salah satu pengobatan tradisional dengan melakukan pemijatan pada titik akupuntur. Titik akupresur yang digunakan untuk mengurangi nyeri persalinan diantaranya adalah Li4, dan SP6 yang dapat mengelola nyeri persalinan. ${ }^{8-10}$

Tehnik Pengurangan nyeri diantaranya adalah

Akupresur. Transcutaneous Electrical Nerve Stimulation (TENS) juga dapat mengurangi nyeri saat persalinan dimana TENS merupakan salah satu pilihan analgesia non-farmakologi yang mulai dipopulerkan penggunaanya dalam mengatasi nyeri persalinan. Elektroda dipasang sejajar T10 dan L1 pada punggung ibu. Metode ini diketahui efektif untuk mengendalikan nyeri selama kala satu persalinan. Dua elektroda lainnya dipasang diantara S2 dan S4 sehingga dapat mengendalikan nyeri selama kala satu persalinan. Tombol kontrol boost memberikan pola stimulasi dermatome yang memiliki intensitas dan frekuensi yang tinggi sehingga dapat mengendalikan nyeri selama kontraksi uterus. ${ }^{11,12}$

Tujuan penelitian ini adalah untuk menentukan pengaruh tehnik akupresur dan TENS terhadap intensitas nyeri persalinan kala I fase aktif.

\section{METODE}

Penelitian ini merupakan penelitian kuantitatif dengan rancangan eksperimental dengan post test only control group desain. Kelompok yang diteliti di bagi menjadi kelompok kontrol dan eksperimental yaitu kelompok akupresur dan TENS. Tempat penelitian wilayah kerja Puskemas Kampar kiri tengah dan Perhentian raja. Pada penelitian ini, dibedakan 
kelompok perlakuan dan kontrol, wilayah kerja Puskesmas Kampar Kiri Tengah menjadi kelompok perlakuan akupresur dan TENS, sedangkan kelompok kontrol diwilayah kerja Puskemas Perhentian Raja.

Populasi dalam penelitian ini adalah semua ibu inpartu kala I fase aktif di wilayah kerja Puskesmas Kampar Kiri Tengah dan Puskesmas Perhentian Raja. Penelitian dilakukan dari Februari sampai April 2014. Jumlah sampel pada penelitian ini 60 responden, yang dibagi menjadi 3 kelompok, yaitu 20 responden untuk perlakuan akupresur, 20 responden untuk perlakuan TENS dan 20 kelompok kontrol.

Intensitas nyeri diukur menggunakan NRS (Numerical Rating Scale) dimana kuesioner ini sudah banyak digunakan untuk pengukuran intensitas nyeri, kuesioner ini menggunakan angka-angka untuk menggambarkan range dari intensitas nyeri. Umumnya pasien akan menggambarkan intensitas nyeri yang dirasakan dengan angka 0-10, dimana angka 0 menggambarkan tidak ada nyeri, sedangkan1-5 menggambarkan nyeri sedang, 6-10 menggambarkan nyeri berat.

Tindakan pemberian akupresur dilakukan oleh peneliti sendiri. Dimana peneliti sudah mengikuti pelatihan akupresur di Lembaga KEPPTI (Kelompok Pencinta Tanaman Obat Indonesia) kota Bekasi kurang lebih 3 minggu. Titik yang digunakan untuk mengurangi nyeri persalinan yaitu titik Li4 dan SP6.

Reiki TENS merupakan suatu alat pijat mesin terapi digital dimana penggunaannya digunakan dititik aku-presur/akupuntur, dalam penelitian ini titik yang dipakai dalam penggunaan alat Reiki TENS dipasang sejajar $T 10$ dan $L 1$ pada punggung ibu, dan elektroda kedua dipasang diantara S2 dan S4.

\section{HASIL DAN PEMBAHASAN}

Setelah dilakukan penelitian, didapatkan sebanyak 20 ibu inpartu kala I fase aktif yang dilakukan akupresur, 20 yang dilakukan TENS dan 20 kelompok kontrol dengan total responden 60 . Pengukuran dilakukan 2 kali pada pembukaan serviks $4 \mathrm{~cm}$ dan $8 \mathrm{~cm}$, setelah itu pengukuran nyeri menggunakan NRS.

Berdasarkan hasil penelitian yang dilakukan pada kelompok akupresur, TENS dan kontrol yang berjumlah masing-masing 20 responden dapat dilihat bahwa mayoritas terdapat pada umur 20-25 tahun dimana pada umur tersebut beresiko rendah.

Tabel 1. Karakteristik responden

\begin{tabular}{|c|c|c|c|c|c|c|}
\hline \multirow{2}{*}{$\begin{array}{l}\text { Karakteristik } \\
\text { Responden }\end{array}$} & \multicolumn{2}{|c|}{ Akupresur } & \multicolumn{2}{|c|}{ TENS } & \multicolumn{2}{|c|}{ Kontrol } \\
\hline & $f$ & $\%$ & $f$ & $\%$ & $\bar{F}$ & $\%$ \\
\hline \multicolumn{7}{|l|}{ Umur } \\
\hline 20-25 tahun & 14 & 70 & 16 & 80 & 12 & 60 \\
\hline 26-30 tahun & 5 & 25 & 2 & 10 & 8 & 40 \\
\hline 31-35 tahun & 1 & 5 & 2 & 10 & 0 & 0 \\
\hline \multicolumn{7}{|l|}{ Pendidikan } \\
\hline SD & 3 & 15 & 3 & 15 & 0 & 0 \\
\hline SMP & 1 & 5 & 3 & 15 & 4 & 20 \\
\hline SMA & 10 & 50 & 9 & 45 & 14 & 70 \\
\hline PT & 6 & 30 & 5 & 25 & 2 & 10 \\
\hline \multicolumn{7}{|l|}{ Pekerjaan } \\
\hline Tidak bekerja & 10 & 50 & 15 & 75 & 17 & 85 \\
\hline Bekerja & 10 & 50 & 5 & 25 & 3 & 15 \\
\hline \multicolumn{7}{|l|}{ Suku } \\
\hline Melayu & 12 & 60 & 14 & 70 & 11 & 55 \\
\hline Jawa & 8 & 40 & 6 & 30 & 9 & 45 \\
\hline
\end{tabular}

Ibu yang melahirkan pertama kali pada umur tua umumnya akan mengalami persalinan yang lebih lama dan merasakan lebih nyeri dibandingkan ibu yang masih muda. ${ }^{15}$

Umur muda cenderung dikaitkan dengan kondisi psikologis yang masih labil, yang memicu terjadinya kecemasan sehingga nyeri yang dirasakan menjadi lebih berat. Umur juga dipakai sebagai salah satu faktor dalam menentukan toleransi terhadap nyeri. Toleransi akan meningkat seiring bertambahnya usia dan pemahaman terhadap nyeri. ${ }^{16}$

Berdasarkan karakteristik responden, mayoritas pendidikan SMA, dilihat dari segi pekerjaan mayoritas tidak bekerja dan mayoritas suku pada penelitian ini adalah suku Melayu. Faktor yang mempengaruhi respon terhadap nyeri persalinan meliputi pendidikan, kepercayaan, budaya, kelelahan dan gangguan tidur, makna nyeri, pengalaman sebelumnya, kecemasan dan adanya tehnik pengurangan nyeri non farmakologi. Dengan adanya tehnik pengurangan nyeri, pengetahuan tentang bersalin dan cara menangani pengurangan nyeri dapat diatasi dan dapat meningkatkan rasa nyaman serta berusaha 
menguasai dan mengontrol dirinya selama persalinan. ${ }^{15,16}$

Tabel 2. Pengaruh akupresur terhadap intensitas nyeri persalinan kala I fase aktif pada pembukaan $4 \mathrm{~cm}$

\begin{tabular}{cccccc}
\hline & \multicolumn{4}{c}{ Akupresur } & \\
\cline { 2 - 5 } $\begin{array}{c}\text { Intensitas } \\
\text { Nyeri }\end{array}$ & Intervensi & \multicolumn{2}{c}{ Kontrol } & p \\
\cline { 2 - 5 } $\begin{array}{c}\text { Pembukaan } \\
\text { cm }\end{array}$ & $\mathbf{f}$ & $\%$ & $\mathbf{f}$ & $\%$ & \\
\hline sedang & 15 & 75 & 6 & 30 & 0,011 \\
berat & 5 & 25 & 14 & 70 & \\
\hline Jumlah & 20 & 100 & 20 & 100 & \\
\hline
\end{tabular}

Ada perbedaan pengaruh intensitas nyeri pada kelompok dilakukan intervensi akupresur dan kontrol pada pembukaan serviks $4 \mathrm{~cm}$, dimana pada kelompok intervensi intensitas nyeri sebagian besar kategori sedang sedangkan pada kelompok kontrol intensitas nyeri mayoritas kategori berat. Hasil uji statistik mendapatkan $\mathrm{p}<0,05$ yang berarti terdapat pengaruh bermakna antara dilakukan intervensi nyeri ringan sebanyak $50 \%$, nyeri sedang $46,7 \%$ dan nyeri sangat berat $3,3 \%$, dan hasil uji statistik dengan nilai $p=0,000$, yang artinya tehnik akupresur efektif dalam mengurangi nyeri persalinan. ${ }^{17}$

Tabel 3. Pengaruh akupresur terhadap intensitas nyeri persalinan kala I fase aktif pada pembukaan $8 \mathrm{~cm}$

\begin{tabular}{|c|c|c|c|c|c|}
\hline \multirow{3}{*}{$\begin{array}{c}\text { Intensitas } \\
\text { Nyeri } \\
\text { Pembukaan } \\
8 \mathrm{~cm}\end{array}$} & \multicolumn{4}{|c|}{ Akupresur } & \multirow{3}{*}{$p$} \\
\hline & \multicolumn{2}{|c|}{ Intervensi } & \multicolumn{2}{|c|}{ Kontrol } & \\
\hline & $f$ & $\%$ & $f$ & $\%$ & \\
\hline sedang & 8 & 40 & 4 & 20 & \\
\hline berat & 12 & 60 & 16 & 80 & 0,301 \\
\hline Jumlah & 20 & 100 & 20 & 100 & \\
\hline
\end{tabular}

Sejalan dengan penelitian yang dilakukan oleh Rusdiatin dan Maulana (2007) tentang pemberian tehnik akupresur terhadap tingkat nyeri persalinan, mendapatkan hasil setelah diberikan akupresur tingkat Nyeri yang dirasakan pada pembukaan serviks $4 \mathrm{~cm}$ disebabkan oleh perubahan serviks dan iskemia rahim, nyeri pada pembukaan $4 \mathrm{~cm}$ ini bersifat viseral. Nyeri ini berasal dari bagian bawah abdomen dan menyebar ke daerah lumbar punggung dan menurun ke paha. Terdapat hubungan yang bermakna dilakukan intervensi akupresur dengan kelompok kontrol pada pembukaan serviks $4 \mathrm{~cm}$, menurut asumsi peneliti, nyeri pada pembukaan $4 \mathrm{~cm}$ bersifat viseral dimana nyeri belum tertuju pada suatu tempat, jadi dengan adanya penekanan atau sentuhan pada titik Sp6 dan Li4 dapat meningkatkan rasa kenyamanan pada ibu. Nyeri viseral ini ditimbulkan oleh karena adanya kontraksi uterus dan dilatasi serviks yang dipersyarafi oleh serabut aferen simpatis dan ditransmisikan kemedula spinalis pada segmen T10-L1 (Thorakal 10-Lumbal 1) melalui serabut saraf delta dan serabut syaraf $\mathrm{c}$ yang berasal dari dinding lateral dan fundus uteri. ${ }^{16,18}$

Pada pembukaan serviks $8 \mathrm{~cm}$ dilakukan intervensi akupresur dengan kelompok kontrol didapatkan tidak ada hubungan yang bermakna dengan nilai $P>0,05$. Menurut asumsi peneliti, nyeri pada pembukaan serviks $8 \mathrm{~cm}$ bersifat somatik karena mendekati kala II persalinan, nyeri pada pembukaan ini ditransmisikan melalui nervus pundendal yang berasal dari S2 dan S4, pada kala ini intensitas nyerinya terasa lebih nyeri dan sudah tertuju dan tajam, nyeri padamasa transisi ini diakibatkan oleh tekanan kepala janin pada pelvis, nyeri yang dirasakan bagian bawah punggung, paha dan tungkai kaki, pada areal vagina dan perineum sensasinya seperti tarikan, tekanan, dan kram. Sensasi nyeri ini dibawa dari perineum ke sakrum 2,3,4 oleh saraf pundendal dan untuk mengurangi nyeri ini biasanya diblok pada reseptor yang paling bawah. ${ }^{15,18}$

Rasa nyeri saat persalinan merupakan hal yang normal terjadi, penyebabnya meliputi faktor fisiologis dan psikologis. Faktor fisiologis yang dimaksud adalah kontraksi, gerakan otot dapat menimbulkan rasa nyeri karena pada saatpersalinan otot-otot rahim memanjang dan kemudian memendek. Serviks juga akan melunak, menipis dan mendatar, kemudian tertarik, saat itulah kepala janin menekan mulut rahim dan membukanya, jadi intensitas nyeri dari awal pembukaan sampai pembukaan lengkap akan meningkatnya nyeri dan semakin sering. Faktor psikologis yang dapat meningkatkan rasa nyeri adalah rasa takut dan cemas yang berlebihan akan mempengaruhi rasa nyeri. Situasi dan kondisi psikologis yang labil memegang peranan penting dalam memunculkan nyeri persalinan yang lebih berat. 
Salah satu mekanisme pertahanan jiwa terhadap stres adalah konversi yaitu memunculkan gangguan secara psikis menjadi gangguan fisik. ${ }^{16,19}$

Tabel 4. Pengaruh TENS terhadap intensitas nyeri persalinan kala I fase aktif pada pembukaan $4 \mathrm{~cm}$

\begin{tabular}{cccccc}
\hline & \multicolumn{4}{c}{ TENS } & p \\
\cline { 2 - 4 } $\begin{array}{c}\text { Intensitas } \\
\text { Nyeri } \\
\begin{array}{c}\text { Pembukaan } \\
\mathbf{4} \text { cm }\end{array}\end{array}$ & Intervensi & \multicolumn{2}{c}{ Kontrol } & \\
\cline { 2 - 5 } $\begin{array}{c}\text { sedang } \\
\text { berat }\end{array}$ & 11 & 55 & $\mathbf{f}$ & $\%$ & \\
\hline Jumlah & 9 & 45 & 14 & 70 & 0,201 \\
\hline
\end{tabular}

Hasil análisis pengaruh antara kelompok dilakukan intervensi TENS dan kontrol terhadap intensitas nyeri pada pembukaan serviks $4 \mathrm{~cm}$, diperoleh bahwa sebagian besar tingkat nyeri kategori sedang pada kelompok TENS, sedangkan kelompok kontrol tingkat nyeri sebagian besar berada pada kategori berat. Namun berdasarkan hasil uji statistik diperoleh nilai $p>0,05$.

Hasil penelitian Yulifah et al (2009) yang meneliti penggunaan stimulasi Transcutaneous Electrical Nerve Stimulation (Tens) mendapatkan menggunakan Tens dapat menurunkan intensitas nyeri dan tingkat kecemasan pada persalinan kala I dan mendapatkan hasil ada perbedaan intensitas nyeri dan tingkat kecemasan sebelum dan sesudah diberikan stimulasi TENS, dengan nilai $\mathrm{p}=0,05$ untuk tingkat nyeri dan $p=0,00$ untuk tingkat kecemasan. ${ }^{20}$

Pemberian TENS tidak berpengaruh pada pembukaan $4 \mathrm{~cm}$, kemungkinan hal ini terjadi karena meningkatnya tingkat stres dan kecemasan ibu, menurut Norwitz (2007) nyeri persalinan umumnya terasa hebat dan hanya 2-4\% ibu yang mengalami nyeri ringan selama persalinan. Persiapan melahirkan tidak berarti bebas dari nyeri dan rasa tak nyaman selama persalinan. Ibu harus mampu menyiapkan diri terhadap terhadap perasaan tersebut secara realistis. Sikap positif terhadap peristiwa persalinan membuat kadar endorfintinggi, peningkatan endorfin ini dapat menurunkan sensifitas nyeri. Ibu yang tidak tahu tetntang peristiwa yang akan terjadi pada persalinan akan menimbulkan takut, cemas sehingga nyeri ibu tidak terkontrol. ${ }^{1,21}$
Tabel 5. Pengaruh TENS terhadap intensitas nyeri

\begin{tabular}{cccccc}
\hline & \multicolumn{4}{c}{ TENS } & p \\
\cline { 2 - 5 } $\begin{array}{c}\text { Intensitas } \\
\text { Nyeri }\end{array}$ & Intervensi & \multicolumn{2}{c}{ Kontrol } & \\
\cline { 2 - 5 } $\begin{array}{c}\text { Pembukaan } \\
\mathbf{8} \text { cm }\end{array}$ & $\mathbf{f}$ & $\%$ & $\mathbf{f}$ & $\%$ & \\
\hline $\begin{array}{c}\text { sedang } \\
\text { berat }\end{array}$ & 13 & 65 & 4 & 20 & \multirow{2}{*}{0,011} \\
\hline Jumlah & 20 & 35 & 16 & 80 & \\
\hline
\end{tabular}

Stres persalinan akan berefek pada peningkatan hormon kortisol yang disekresikan oleh korteks adrenal, merupakan hormon yang disekresikan oleh tubuh dalam berespon terhadap stres fisik dan emosi. Kadar kortisol dan katekolamin meningkat saat persalinan dan berkolerasi dengan kecemasan serta nyeri akan semakin hebat. Pengeluaran kortisol diaktifkan terutama oleh stres negatif seperti rasa takut, cemas dan depresi dan tidak ada kontrol.22-24

Aktivasi sistem stres dan kecemasan yang berlebihan ini dapat memimpin perubahan perilaku pada persepsi nyeri, sehingga nyeri semakin hebat, ibu menjadi tegang dan melawan kontraksi. Dengan demikian, memberikan stimulasi kulit dengan menggunakan TENS akan dapat menjadikan efek biasa disebabkan stres yang dapat memimpin perubahan perilaku terhadap nyeri, sehingga dapat menurunkan kemam-puannya dalam mengatasi rasa nyaman selama persalinan. ${ }^{25}$

Pemakaian TENS pada kelompok intervensi pada pembukaan $8 \mathrm{~cm}$ terdapat hubungan yang bermakna terhadap intensitas nyeri hal ini terjadi karena TENS merupakan tehnik non invasif sederhana, selama pemberian TENS getaran pijatan menggunaakan arus listrik yang dihasilkan oleh portable pulse generator dan diberikan melalui permukaan kulit yang sehat melalui bantalan hantaran elektroda. Cara pemberian Reiki TENS secara selektif akan mengaktifkan serat raba berdiameter besar $(A \beta)$ tanpa mengaktifkan serat nociceptive berdiameter lebih kecil (Aa dan $\mathrm{C}$ ), sehingga menghasilkan subtansi analgesik segmental yang dikeluarkan otak dengan cepat dan terlokalisir pada dermatom yang bekerja pada sistim syaraf pusat dan perifer untuk mengurangi nyeri. ${ }^{20,26}$ 
Penelitian Paliyama (2004) tentang perbedaan efek terapi arus interferensi dengan TENS dalam mengurangi nyeri pada penderita nyeri punggung bawah mendapatkan hasil terapi arus interferensi ada perbedaan berupa pengurangan nyeri yang ditunjukkan dengan penurunan nilai nyeri, begitu juga dengan pemberian terapi TENS juga dapat mengurangi nyeri punggung bawah, terapi arus interferensi sama baiknya dengan TENS. ${ }^{27}$

TENS memiliki beberapa keunggulan karena merupakan tehnik non-invasif yangdigunakan dan dapat memberikan analgesi yang mudah digunakan, portabel dapat memberikan analgesi secara terusmenerus untuk berbagai kondisi. Dalam bidang kebidanan sebagian besar TENS telah dipromosikan untuk digunakan dalam nyeri persalinan dan efektif dalam mengurangi nyeri persalinan. TENS dapat digunakan untuk menghindarkan intervensi analgesik lain yang dapat mengakibatkan efek terhadap ibu dan bayi. 27,28

Faktor lain kemungkinan terjadi pengurangan nyeri pada persalinan terjadi apabila ibu mampu atau menanggulangi diri agar selama persalinan merasa aman, sikap positif terhadap pemberian terapi TENS ini meningkatkan rasa nyaman, peristiwa persalinan membuat kadar endorfin tinggi, peningkatan kadar endorfin ini dapat menurunkan sensitifitas nyeri. Penelitian yang dilakukan oleh Tumblin dan Simkin (2001) tentang persepsi ibu hamil tentang peran bidan ketika persalinan menyimpulkan bahwa ibu mengharapkan agar bidan menyediakan waktu untuk memberi rasa nyaman, dukungan emosional dan dukungan informasi. ${ }^{29}$

Asumsi peneliti menunjukkan hasil bahwa stimulasi listrik oleh TENS mengurangi nyeri melalui hambatan nosiseptif pada tingkat presinaptik pada kornu bagian dorsal. Sehingga menghambat transmisi ke sentral. Rangsangan listrik pada kulit mengaktifasi ambang rendah serabut syaraf bermielin. Input aferen dari serabut ini menghambat propagasi nosiseptif yang dibawa oleh serabut-serabut $\mathrm{C}$ kecil tak bermielin dengan menghambat transmisi sepanjang serabut syaraf ini ke target sel T yang terdapat pada subtansia gelatinosa kornu dorsal. Mekanisme analgesi yang dihasilkan oleh TENS dapat dijelaskan dengan teori pengontrolan gerbang (Gate Control Theory). Teori ini menjelaskan bahwa serabut syaraf dengan diameter kecil yang membawa stimulus nyeri akan melalui pintu yang sama dengan serabut yang memiliki diameter lebih besar yang membawa impuls raba mekanoreseptor, apabila kedua serabut syaraf tersebut secara bersama-sama melewati pintu yang lebih kecil. Gerbang biasanya tertutup, menghalangi secara konstan transmisi nosiseptive melalui serabut C mencapai ke sel-T. jika timbul rangsangan nyeri perifer, informasi dibawa oleh serabut $\mathrm{C}$ mencapai ke sel $\mathrm{T}$ dan gerbang akan terbuka, menyebabkan transmisi sentral ke thalamus dan korteks dimana impulsa kan diinterpestasikan sebagai nyeri. ${ }^{26,29}$

\section{KESIMPULAN}

Akupresur dan TENS dapat berpengaruh terhadap intensitas nyeri persalinan kala I fase aktif. Akupresur lebih baik digunakan pada pembukann serviks $4 \mathrm{~cm}$ dan TENS baik digunakan pada pembukaan serviks $8 \mathrm{~cm}$.

\section{UCAPAN TERIMA KASIH}

Terima kasih kepada STikes Hang Tuah Pekanbaru atas kesempatan yang diberikan untuk melanjutkan pendidikan. Kepada Wilayah kerja Puskesmas Kampar Kiri Tengah dan Perhentian Raja kabupaten Kampar Provinsi Riau atas fasilitas yang telah diberikan.

\section{DAFTAR PUSTAKA}

1. Norwitz E, Schorge J. At a glance obstetri dan ginekologi. Alih bahasa: Artsiyanti D. Jakarta: Erlangga; 2007.

2. Reeder S, Martin L, Griffin D. Keperawatan maternitas: kesehatan wanita. Edisi ke-18 Vol $1 .$. Mardella, editor bhs Indonesia. Jakarta: EGC; 2013. hlm. 649-51.

3. Pusdiknakes-JHPIEGO. Panduan Pengajaran asuhan kebidanan fisiologis bagi dosen diploma III kebidanan. Buku 1 Konsep Asuhan Kebidanan. Jakarta; 2003. hlm. 18-9.

4. WHO. Major causes of maternal morbidity and mortality in pregnancy and childbirth. The Progress In Reproductive Health Reseach. 2001;56. 
5. Ramamurthy S, Alanmanou E, Rogers J. Decision making in pain manajemen. Edisi ke-2. Philadelphia: MOSBY Elsevier; 2006.

6. Tournair M, Theau-Yonmeau A. Complementary and alternative to pain relief during labor. Evid Based Complement Altrnate Med. 2007;4(4):40917.

7. Burns E, Blamey C. Using aromatherapy in childbirth. Nursing Times. 1994;90(9):54-60.

8. Bagaskoro S. Buku sakti pijat untuk kesehatan refleksi, akupresur dan akupuntur. Yogyakarta: Pinang Merah Publisher; 2011

9. Chung L, Kuo S, Huang C. Effects of Li4 and BL 67 acupressure on labor pain and uterine contraction in the first stage of labor. Journal of Nursing Reseach. 2003;11(4).

10. Lee M, Chang S, Kang D. Effect of SP6 acupressure on labor pain and lengt of delivery time in women during labor. The Journal of Alternative and Complementary Medicine. 2004; 10(6): 959-65.

11. Johnson, R. Taylor, W. Keterampilan dasar praktik klinik kebidanan (skills for midwifery practice). Alih bahasa : Esty W. Edisi ke-3. Jakarta: EGC; 2013.

12. Bonny D, Meiliasari Y. Persalinan Normal Tanpa Rasa Sakit. Yogyakarta: Puspa Swara; 2004. Hal. 57-9.

13. Sastroasmoro S, Ismael S. Dasar - dasar Metodologi Penelitian Klinis. Edisi ke-4. Jakarta: CV Sagung Seto; 2011.

14. Ho F, Irene L, Grace M. Intrapartum transcutaneous electrical nerve stimulation for pain relief and outcome of labour. Hongkong J Gynaecol Obstet Midwifery. 2011;11:12-8.

15. Bobak I, Lowdermilk D, Jensen M, Perry S. Buku ajar keperawatan maternitas (maternity nursing). Edisi ke-4. Alih bahasa: Wijayarini M. Editor bahasa Indonesia: Komalasari R. Jakarta: EGC; 2005.

16. Andarmoyo S, Suharti. Persalinan tanpa nyeri berlebihan : konsep dan aplikasi manajemen nyeri persalinan. Yogyakarta: Ar-Ruzz Media;2013:52-3.

17. Rusdiatin I, Maulana D. Pengaruh pemberian tehnik akupresur terhadap tingkat nyeri persalinan kala I di RS Rajawali Citra Potorono Banguntapan
Bantul. Yogyakarta: Seminar Nasional Teknologi; 24 November 2007. ISSN 1978-9777.

18. Maryunani A. Nyeri dalam persalinan: tehnik dan cara penanganannya. Jakarta: Trans Info Medika; 2010.

19. Kashanian M, Shahali S. Effects of acupressure at the Sanyinjiao Point (SP6) on the process of active phase of labor in nulliparas women.The Journal of Maternal-Fetal and Neonatal Medicine. 2010;23(7):631-8.

20. Yulifah R, Purnomo W. Penggunaan stimuli transcutaneous electrical nerve stimulation (Tens) dapat menurunkan intensitas nyeri dan tingkat kecemasan pada persalinan kala I. The Indonesian Journal of Public Health. 2009; 5(3): 119-23.

21. Budhiastuti S, Hakimi M, Suhartini, Soejono S. Konseling dan Mekanisme Koping Ibu Bersalin. Journal of Educational, Health and Community Psycology; 1(1). ISSN: 2088-3129.

22. Leifer G. Maternity nursing. Edisi ke- 9. Philadelphia: Elsevier Saunders. 2005.

23. Kabat. Chronic pulmonary lung disease is a sress speeds HIV desease progressional a psyconeuro immunology case presentation. Surabaya: Simposium Nasional Perdana Psikoneuro Imunologi; 24 Juli 2004.

24. Alehagen S, Wijma K, Wijma B. Fear during labor. Acta Obstetrics Ginecology Scandinavia. 2001; 80:315-20.

25. Klossner N, Hatfi N. Introductory maternity dan pediatric nursing. Philadelphia: Lippicott Williams dan Walkins; 2006.

26. Fraser D, Cooper M, Fletcher G. Myles buku ajar bidan (Myles Textbook for Midwives). Alih bahasa: Rahayu S. Editor bahasa Indonesia: Karyuni P. Edisi ke-14. Jakarta: EGC; 2009. hlm. 467-8

27. Paliyama J. Perbandingan efek terapi arus interferensi dengan TENS dalam pengurangan nyeri pada penderita nyeri punggung bawah musculoskeletal (tesis). Semarang:Universitas Diponegoro; 2004.

28. Wright $A$. Exsploring the evidence for using TENS to relieve pain. Nursing Practice Review Pain Management/Non-pharmalogical. 2012;108(11): 
20-3.

29. Tumblin A, Simkim P. Pregnant women's preceptions of their nurse's role during labor and delivery. Birth. 2001; 28(1). 